\title{
Modelling Study on Learning Affects for Classroom Teaching/Learning Auto-Evaluation
}

\author{
Minyu Pan ${ }^{1}$, Jing Wang ${ }^{1,2}$, Zuying Luo ${ }^{1,2, *}$ \\ ${ }^{1}$ College of Information Science and Technology, Beijing Normal University, Beijing, China \\ ${ }^{2}$ Engineering Research Center of Virtual Reality and Applications, Ministry of Education, Beijing, China \\ Email address: \\ pandadadahu@163.com (Minyu Pan).j.wang@bnu.edu.cn (Jing Wang), luozy@bnu.edu.cn (Zuying Luo) \\ ${ }^{*}$ Corresponding author
}

To cite this article:

Minyu Pan, Jing Wang, Zuying Luo. Modelling Study on Learning Affects for Classroom Teaching/Learning Auto-Evaluation. Science Journal of Education. Vol. 6, No. 3, 2018, pp. 81-86. doi: 10.11648/j.sjedu.20180603.12

Received: March 21, 2018; Accepted: April 30, 2018; Published: June 20, 2018

\begin{abstract}
In studies on classroom teaching auto-evaluation, we have achieved some remarkable results in Classroom Attendance Auto-management, learning attention \& facial expression auto-analysis. For further utilizing learning affects to auto-evaluate classroom teaching/learning effects, we watch a large number of classroom videos. Then, based on the stimulus-response mechanism, we use learning facial expressions \& attention to categorize students' learning affects (SLA) and construct a SLA transfer model. At last, we simply describe how to use SLA analysis results to auto-evaluate the classroom teaching/learning effects. This work lays a theoretical foundation for the studies on learning facial expressions and learning affects for classroom teaching/learning auto-evaluation.
\end{abstract}

Keywords: Learning Affect, Classroom Evaluation, Affect Modelling, Facial Expression Recognition

\section{Introduction}

With the deepening of research, people have found that emotion plays an important role in student learning. Bloom has said that the cognition can change emotion, and emotion can change the cognition. A quarter part of the differences in the performance of individual students can be explained by the emotional characteristics [1]. Therefore, when we conduct evaluations on students, in addition to evaluating students' cognitive development, we must also evaluate the development of students' learning affects. If we do not evaluate it, schools will not be able to get the evidences for revising courses and teaching methods for emotional teaching goals [1].

Student learning emotion evaluation began with Bloom's educational object taxonomy, but at present, the theoretical research on learning emotional evaluation is still in the initial stage. The domestic scholars' research on learning emotional goals is more about the simple revise of Bloom's emotional goals instead of forming localized emotional goals [2-3]. The book Education Evaluation edited by Bloom was devoted to a detailed description of affective evaluation techniques. He believes that methods for evaluating emotions in learning include observations, talks, questionnaires, and scales. The methods of observations and talks are relatively subjective, while scales and questionnaires can provide a more objective result and be able to measure learning affects of large groups of students. For example, the research group of Professor Cai uses the scale measurement methods to perform learning affect measurements on 831 students in grades 2-6 of primary school [3].

In the classroom teaching process, course teachers and experts evaluate students' learning attitudes mainly by observing students' learning behaviors, and indirectly evaluate students' learning affects [4-5]. Because affects originate from the psychological mechanism and are implicit, the same affectivity can be expressed by different behaviors, and the same behavior may be the result of different emotional effects. Compared with cognitive learning, the correlation between emotional inner experience and actual behavior is weak [5]. Therefore, it is difficult for classroom evaluation to evaluate learning affect quantitatively. Even so, with the developments of technology, many researchers try to evaluate students' learning affects by means of technology, especially in the e-learning environment. For example, Scotti 
etc. developed a tool for recognizing emotions during e-learning processes by combing quantitative indexes extracted from four physiological signals [9]. Krithika etc. construct a Student Emotion Recognition System to identify and monitor emotions of students based on eyes and head movement and provide feedback to instructors to improve learner experience [10].

In order to quantify the student's learning affect in the classroom teaching process and then automatically evaluate the classroom teaching effect based on the results of each student's learning affect analysis, we have already carried out some researches on the automatic classroom attendance, student learning attention analysis, learning facial expression analysis, etc. and achieved satisfactory results. Based on the stimuli-response mechanism, we observed and analyzed teacher's behaviors and students' reactions in the classroom teaching process by watching a large number of classroom teaching videos. We summarized teachers' teaching activities and the stimulus-response types between teachers and students. Then students' learning affects were classified and students' learning affect transfer model was constructed. Finally, how to evaluate the effects of classroom learning automatically based on the results of learning affect analysis was discussed. This work provides a theoretical basis for the study of learning expressions and learning affects in automatic evaluation of classroom teaching.

\section{Foundation of Research: Automatic Analysis of Learning Behavior in Classroom Teaching}

In recent years, with the rapid development of information technology, especially the introduction of deep learning technology into the computer vision [7], the learning behavior of each student in the classroom can be automatically analyzed by computers. In the field of automatic evaluation of classroom teaching, we used machine-learning techniques to conduct research on classroom automatic attendance, visual analysis of students' attention, and students' facial expression analysis, and achieved satisfactory research results.

\subsection{Face Detection and Face Recognition Based Classroom Automatic Attendance}

As shown in Figure 1, we can use the deep learning technology to process the classroom instructional video and perform face detection and face recognition for each student to automatically judge whether the student enters the classroom and whether the head posture shows abnormal. In addition, we can also make real-time attendance of five abnormal situations, including being late, leaving early, skipping school, going in and out of the classroom at random, and not listening carefully.



Figure 1. Face detection and face recognition based classroom automatic attendance.

\subsection{Visualized Analysis of Student Attention Based on Head Posture Recognition}

The visual analysis of students' attention is to locate the students' attention through technical means. As shown in Figure 2(a), first, we use the camera installed above the center of the blackboard to perform head posture recognition on the students who attend the lecture, thus we can obtain the three-dimensional coordinates of the student's head posture (mark at the tip of the student's nose) as shown in Figure 2(b). Next, the student's line of sight can be calculated based on the student's head position $(\mathrm{X} / \mathrm{Y} / \mathrm{Z})$ and three-dimensional coordinates of the head posture. Finally, the student's point of view is marked in the instructional video shot by the rear camera. As shown in Figure 2 (a), the student's point of view falls below the teacher's left ear.

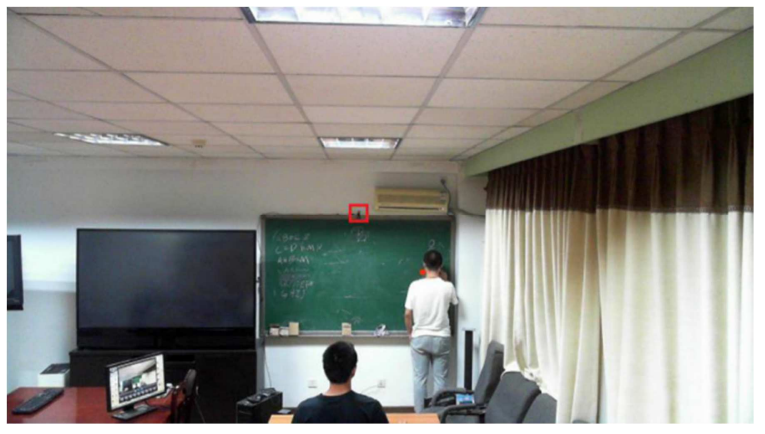

(a). The installation position of the front camera and the visualization of the visual projection point of the subject.

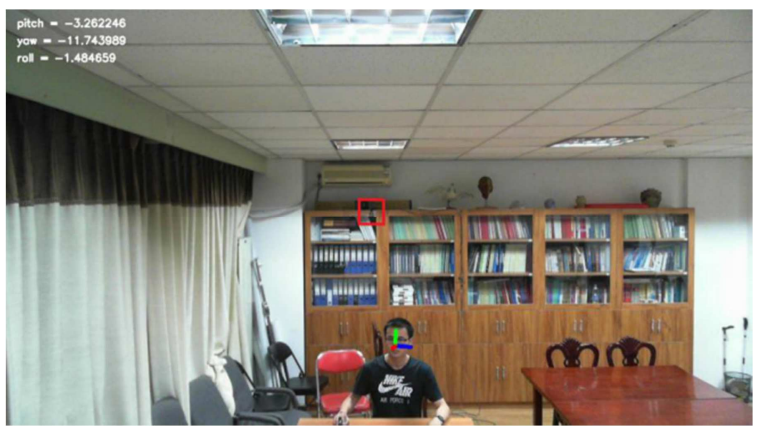

(b). The installation position of the rear camera and the visualization of the head posture of the subject.

Figure 2. Head posture recognition based visualized analysis system of student learning attention and its display effect. 


\subsection{Student's Learning Expression Analysis}

Based on the learning expression recognition system shown in Figure 3, the five kinds of expressions of joyful, surprised, confused, focused, and distracted shown in Figure 4 can be recognized [8].

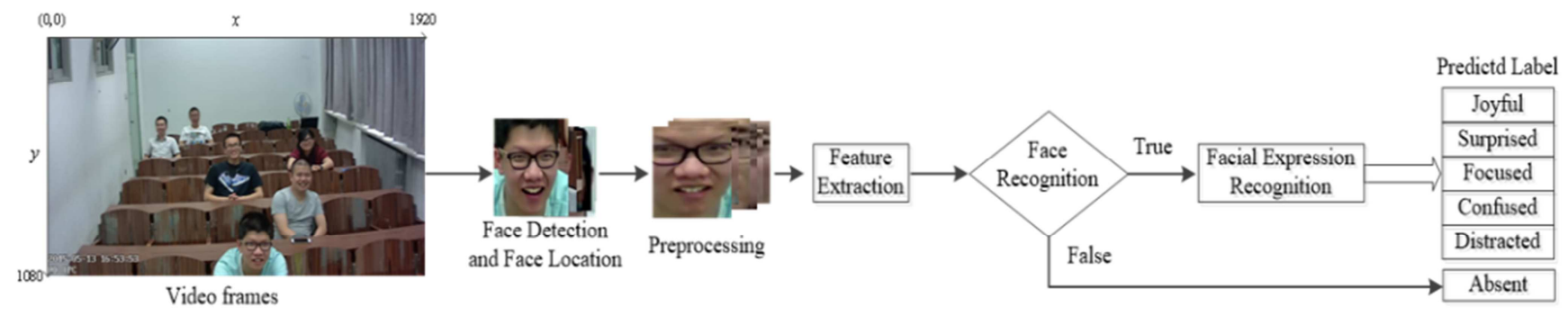

Figure 3. Learning Expression Recognition based Classroom Teaching Automatic Evaluation System.

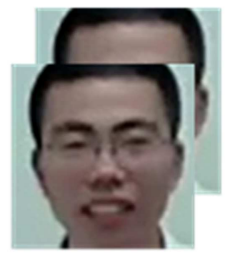

Joyful

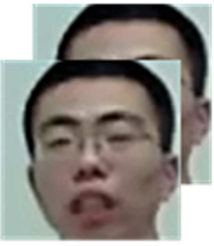

Surprised



Confused

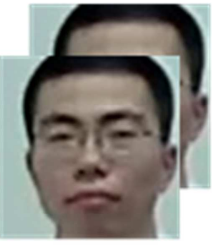

Focused

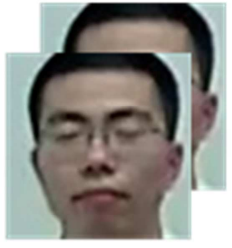

Distracted

Figure 4. Five kinds of facial expressions when listening

\section{Stimulus-Response Mechanism Based Classroom Observation}

The biggest obstacle of quantified evaluation on classroom teaching is the inability to quantify the learning affects of a large number of students. At present, evaluation indicators such as attracting students' attention, motivating students' curiosity, and promoting students' thinking commonly used in classroom evaluation are all from classroom observation of professional evaluators [3-6]. In this paper, classroom students' affects and teachers' activities were observed based on the attention and expressions of emotion.

\subsection{Teacher's Activities in Class}

In actual classroom teaching, many of the activities of teachers affect student's learning and emotional state. From the teacher's point of view, a more effective method for improving the quality of teaching is to encourage students through some stimuli and inspire students' learning motivation. From the student's point of view, the students also want teachers to take some fresh teaching methods to arouse their interest in the knowledge so that the learning process will not be too boring. Furthermore, both teachers and students hope to have a relaxed and enjoyable atmosphere in class. Teachers are in the dominant position in class, and their activities or behaviors play a key role in the classroom atmosphere and students' emotions. As shown in Table 1, with the observation method, we classify the activities of teachers in class into three categories. Each type of activity contains a number of different instructional modes or methods:

Behavior. In class, teachers will make a series of presentations, such as lecturing, blackboard-writing, multimedia presentations, oral presentations, and material object demonstrations. These active behaviors take teaching knowledge as the main purpose, while encouraging students and activating students' learning motivation through some supporting tools.

Message. Teachers publish messages in the classroom, such as raising questions, asking students to answer questions, arranging group tasks, etc. They hope to receive students' responses and feedbacks in order to grasp the students' learning situation. According to the learning situation, teachers can adjust the teaching content and strategies. At times, students can also be alerted by messages to increase their attention.

Evaluation. In class, teachers make immediate comments on students' behavior and the results of Q\&A. For example, the teacher criticizes the students who do not listen carefully, and praises the students who answer the questions correctly. On the one hand, they could restrain the students' behaviors in class, and on the other hand, they could encourage the students.

\subsection{Stimulus-Response Types}

As shown in Table 1, the intensity of incentives induced by different teaching activities is different. What's more, in the same type of teaching activity, the incentive intensity induced by different teaching forms may also be different. To this end, we divided the incentive intensity of different teaching activities into three types, i.e., weak incentives, slightly strong incentives, and strong incentives, based on whether or not the incentives can activate students' learning motivation, whether or not they can improve students' interest in learning, and 
whether or not they will have a greater degree of emotional transfer.

Weak incentives. The weak incentive cannot obviously activate the students' learning motivation and interest. Most of the students' facial expressions will not change too much. In addition, some of the students cannot concentrate their attentions. Thus, the impact of weak incentives on inducing students' positive learning affects is small. The general teaching behaviors in the Behavior and Message are all weak incentives, such as lecturing, blackboard writing, self-study, etc. The degree of teacher-student interaction with such behavior or message is not high. Therefore, it is difficult to stimulate students to have positive learning affects by these ways.

Slightly strong incentives. Compared with weak incentives, slightly strong incentives have a more pronounced effect on activating students' motivation and interest in learning and encouraging students to develop positive learning affects. The multimedia and oral presentations of Behavior are slightly strong incentives. In modern classes, with the development of information technology, teachers are no longer just "say" knowledge. Instead, they often use multimedia tools, such as audio, video, PPT, etc. to assist instructions. When viewing pictures, music, and video, the students have demonstrated a clear concentration, and the majority of students are in the emotional state of Concerned. A few students will be dancing, showing the emotion of excited. The same is true of oral presentations such as giving examples and storytelling, which are all slightly strong incentives.

Strong incentives. Strong incentives are most effective in stimulating students' motivation and interest in learning and inducing emotion transfer. Material object demonstration in Behavior such as display of teaching equipment and demonstration of experimental operations, and Evaluation are all strong incentives. In some courses, teachers will bring some teaching equipment and laboratory equipment to the classroom for spot demonstration. Most students are curious about experimental instruments, experimental procedures, and experimental results. Under the guidance of the teacher, they will think about the principles that produce the result, so that they will be at a high level of positive emotions. The Evaluation differs from other teacher activities, in that it has specific objects and the one being evaluated is the object of evaluation. Therefore, the incentive intensity of Evaluation is also for the person being evaluated. When the student answers the question and is praised by the teacher, the student will induce positive emotion. However, when the student is criticized in the classroom, the student may have negative emotion. In the subsequent class, such emotions will dominate the student for a period, causing the student's learning affect to transfer to a greater degree, upward or downward.

Of course, the different types of incentives in the classroom are mutually transforming. For different students, the effect brought by the same incentive is sometimes quite different. For example, teaching activities like raising questions and asking students to answer questions are weak incentives for students who have not been asked to stand up and answer questions. However, for students who are being questioned, such teaching activities belong to strong incentives, and the student may show high-level positive emotions such as Concerned and Thinking.

Table 1. Incentive Categories Generated by Teacher Activities.

\begin{tabular}{|c|c|c|c|c|}
\hline \multirow[t]{2}{*}{$\begin{array}{l}\text { Teacher } \\
\text { activities }\end{array}$} & Behavior & $\begin{array}{l}\text { A series of teacher's presentations behaviors in class } \\
\text { aimed to complete the teaching, encourage and } \\
\text { stimulate students' learning motivation, often } \\
\text { accompanied by message. }\end{array}$ & $\begin{array}{l}\text { General teaching behavior: lecturing, } \\
\text { blackboard-writing } \\
\text { Multimedia means: audio, video, PPT, etc. } \\
\text { Oral presentation: storytelling, giving } \\
\text { examples, telling jokes, etc. } \\
\text { Material object demonstration: teaching } \\
\text { equipment, experimental operation, etc. }\end{array}$ & $\begin{array}{l}\text { Weak incentive } \\
\text { Slightly strong } \\
\text { incentive } \\
\text { Strong incentive }\end{array}$ \\
\hline & $\begin{array}{l}\text { Message } \\
\text { Evaluation }\end{array}$ & $\begin{array}{l}\text { Instruction that teachers provide in the hope of } \\
\text { receiving students' responses aimed to encourage and } \\
\text { activate students' learning motivation. } \\
\text { Teacher's Evaluation of Students' behavior in Class. }\end{array}$ & $\begin{array}{l}\text { Assigning tasks, such as: group discussions } \\
\text { Raising questions, Asking students to answer } \\
\text { questions } \\
\text { Praise, Criticism }\end{array}$ & $\begin{array}{l}\text { Weak incentive } \\
\text { Strong incentive }\end{array}$ \\
\hline
\end{tabular}

\section{Antenna-Type Learning Affect Transfer Model Based on Stimulus-Response Mechanism}

\subsection{Learning Affect Classification Based on Attention and Expression}

In order to conduct learning affect measurements on numerous students in a fully automatic and uninterrupted manner during the classroom teaching process, we classify learning affects based on attention and expression. According to the needs of classroom evaluation, we classify the students' classroom learning affects into the following 6 categories through observation.

Concerned. If a student focus on the blackboard during the class but has no special facial expressions, it indicates that the student is concerned about the content the teacher is teaching. That is, the student gives his/her attention on the class and it is a positive learning affect.

Curiosity. The students looking at the blackboard or the teacher and at the same time displaying surprise on their faces shows that the students are curious about the knowledge. It is a very positive learning affect because it shows that the teacher's teaching strategy stimulates the students' interest.

Thinking. That students staring at the blackboard or teacher and frowning or looking confused suggests the students are in the emotional state of thinking, which is a positive learning 
affect. It indicates that what the teacher taught was difficult causing students to think. However, if there are too many students lost in thought, it means that teachers should moderately reduce the difficulty of teaching content.

Comprehension. If the students look at the blackboard or the teacher and they have a pleasant expressions on their faces at the same time, we can say that the students are in an emotional state of comprehension. This is a positive learning affect as well and shows that the students understand the teaching content. However, if too many students are in this emotional state, it means that teachers can appropriately improve the difficulty of teaching content.

Disregard. If a student does not follow the teacher during class, but there is no negative expressions such as anger, disgust, sadness, etc., it indicates that the student is indifferent to the teaching content of the teacher. In other word, the student is in the emotional state of disregard, which is a negative one of learning affects.

Disgust. Not only do the students not looking at the blackboard, but they also showing negative expressions that indicates the student is in the emotional state of disgust, which is a very negative learning affect. It may results from the reason that the student is not able to understand the contents the teacher says, or there are some other personal reasons affecting his learning affect.

According to the above definitions of six learning affects, we can automatically identify and analyze learning affects of students based on the results of attention analysis and expression analysis. What's more, we can apply the analysis results of learning affects on the evaluations of the learning status of students and the effectiveness of the teaching of teachers.

\subsection{Antenna-Type Learning Affect Transfer Model}

A goal of classroom teaching is the teacher constantly stimulate and motivate the students' learning interest by the means of lecturing, asking questions, presentations, etc., causing the students to keep in the learning emotional state of being interested in teaching contents for a long period of time. According to the theory of classroom management, when students are content to have understood the contents of the lecture, teachers should increase the difficulty of teaching contents for triggering students to return to other learning mental states such as Concerned, Thinking, and Curiosity. Moreover, when students are in the state of Disregard or even Disgust, teachers should reduce teaching difficulty or throw an interesting content or question to free students from negative learning affects and enter positive learning affects like Concerned, Thinking, and Curiosity.

Based on the stimulus-response mechanism, we constructed an antenna-type learning affect transfer model as shown in Figure 5 using the six learning affects defined above. The six kinds of learning affects in the picture are hierarchical. From high to low, they are Curiosity/Thinking, Comprehension, Concerned, Disregard, and Disgust. Although Comprehension is a goal pursued by everyone in terms of teaching effectiveness, Curiosity/Thinking can generate more motivation for learning from the psychological perspective. Therefore, Curiosity/Thinking have a higher level of learning affects.

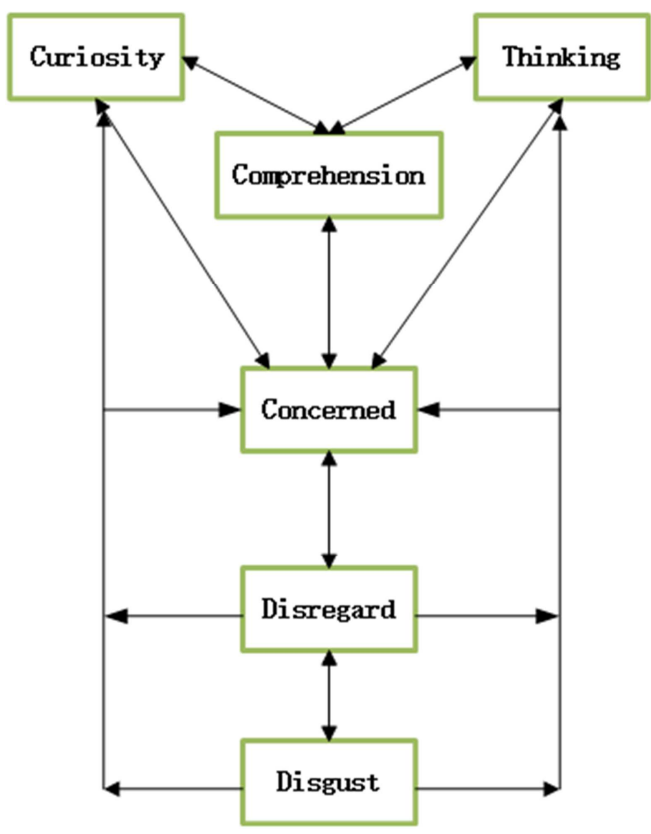

Figure 5. Antenna-type learning affect transfer model.

From the antenna-type learning affect transfer model based on the stimulus-response mechanism, the following transfer rules for learning affects can be defined.

Rule 1: The upward transfer rule of learning affect based on positive strong incentives. The upward transfer of learning affect requires positive incentives. Teachers encourage students by displaying the spirit of enthusiasm, interesting extracurricular knowledge, new knowledge points, and throwing open questions so that the students' learning affect can be transferred upwards from Concerned to Curiosity/Thinking and Comprehension or from Disregard/Disgust to Curiosity/Thinking, Comprehension, and Concerned.

Rule 2: The natural downward transfer rule of learning affect without incentives. When teachers do not provide incentives during class teaching, for example, students are studying or practicing and teachers sit reading books instead of touring the classroom, students' learning affects may naturally transfer downwards from high to low, such as from Concerned to Disregard.

Rule 3: The rule of alternating strong and weak incentives. In the course of normal classroom teaching, the teacher should exert a strong/weak alternation, so that the students' learning affects are in a better transfer pace. In particular, if keeping applying a strong incentive, students will also appear emotional downward transfer and feel tired, that often happens in the open class. In fact, in the teaching process, when students appear to transfer to lower levels of affects, such as from Concerned to Disregard, they require a strong incentive to pull learning affect from Disregard to Curiosity/Thinking directly. Then teachers maintain a 
relatively gradual teaching rhythm in order to make students' affects naturally drop from Curiosity/Thinking to Concerned.

\section{Quantitative Evaluation of Classroom Teaching Based on Learning Affects}

Based on the six types of learning affects, through attention analysis and facial expression analysis, it is possible to analyze the learning affects of all students in class and then evaluate the effects of classroom teaching.

In learning affect analysis, we sampled a $T_{0}$-minute lesson $\mathrm{N}$ times. For a specific student $\mathrm{i}$, he was in the state of Comprehension $N K_{i}$ times, Thinking $N T_{i}$ times, Curiosity $N S_{i}$ times, Concerned $N A_{i}$ times, Disregard $N I_{i}$ times and Disgust $N B_{i}$ times. The sum of these six components is $\mathrm{N}$. For the student $i$, the degree of attractiveness of this class can be calculated as:

$$
\text { attractiveness }_{i}=\left(N K_{i}+N T_{i}+N S_{i}+N A_{i}\right) / \mathrm{N}
$$

The degree of motivating student's curiosity can be calculated as:

$$
\operatorname{curiosity}_{i}=N S_{i} / N
$$

The degree of motivating student's thinking can be calculated as:

$$
\text { thinking }_{i}=N T_{i} / N
$$

For a class with $\mathrm{M}$ students, whether this class is attractive can be evaluated as:

$$
\text { attractiveness }=\frac{1}{M \times N} \sum_{i=1}^{M}\left(N K_{i}+N T_{i}+N S_{i}+N A_{i}\right) / N
$$

Whether this class motivates the students' curiosity can be evaluated as:

$$
\text { curiosity }=\frac{1}{M \times N} \sum_{i=1}^{M} N S_{i}
$$

Whether this class motivates the students' thinking can be evaluated as:

$$
\text { thinking }=\frac{1}{M \times N} \sum_{i=1}^{M} N T_{i}
$$

\section{Conclusion}

Based on the stimulus-response mechanism, this paper firstly classifies students' learning affects according to students' expressions and attention. Then we observe large numbers of classroom teaching videos and construct an antenna-type learning affect transfer model. Finally, a method is proposed to evaluate the classroom teaching effects based on learning affects. It solves the problem that current classroom teaching evaluation method is difficult to analyze quantitatively teaching indicators such as learning interest, curiosity, and students' attention in classroom teaching. This paper provides a theoretical preparation for realizing the fully automatic and undisturbed monitoring and evaluation of these indicators.

\section{Acknowledgements}

This work has been supported by the National Natural Science Foundation of China (NO. 61274033, NO. 61271198).

\section{References}

[1] Bloom etc. Educational Evaluation [M]. East China Normal University Press, 1987 edition.

[2] Jihui Li. How to evaluate emotion, attitude and values [J]. Educational Science Research, 2006, 02:23-26.

[3] Cai Min. A Study on the Evaluation of Elementary Student Affection in Mathematics Learning [J]. Education Science, 2010, 26(1): 26-30.

[4] Kaifeng Liu and Xiaoguo Lv. The Conception of Mathematics Learning Emotion Evaluation Indicator System [J]. Journal of Higher Correspondence Education (Natural Sciences), 2009, 26(1): 26-30.

[5] Huili Tang. Research on the Evaluation of Student's Studying Emotion [D], Henan: Henan University, 2009.

[6] Yi Shen and Yunhuo Cui. Class Observation: Towards professional listening and evaluation [M]. East China Normal University Press, 2008.

[7] Chongsheng Zhang. Deep Learning: Principles and Application Practices [M]. Publishing House of Electronics Industry, 2016.

[8] Chuangao Tang, Pengfei Xu, Zuying Luo, etc., Automatic Facial Expression Analysis of Students in Teaching Environment [C]. 10th Chinese Conference on Biometric Recognition (CCBR), LNCS 9482, 2015: 439-447.

[9] Scotti S etc. Automatic quantitative evaluation of emotions in E-learning applications [C]. Engineering in Medicine and Biology Society, Annual International Conference of the IEEE, 2006: 1359-1362.

[10] Krithika etc. Student Emotion Recognition System (SERS) for e-learning Improvement Based on Learner Concentration Metric [J]. Procedia Computer Science, 2016, 85: 767-776. 